\title{
Challenges and Opportunities in Academic Hospital Medicine: Report from the Academic Hospital Medicine Summit
}

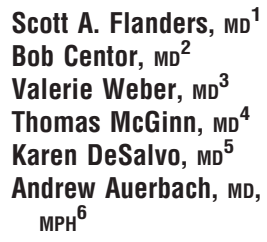

Scott A. Flanders, MD ${ }^{1}$ Bob Centor, MD ${ }^{2}$ Valerie Weber, $\mathrm{MD}^{3}$ Thomas McGinn, MD ${ }^{4}$ Andrew Auerbach, MD, $\mathrm{MPH}^{6}$

\author{
${ }^{1}$ Division of Internal Medicine, University of Michigan, Ann Arbor, Michigan. \\ ${ }^{2}$ University of Alabama Birmingham School of Medicine, Birmingham, Alabama. \\ ${ }^{3}$ Geisinger Clinic, Danville, Pennsylvania. \\ ${ }^{4}$ Mount Sinai School of Medicine, New York, New York. \\ ${ }^{5}$ Tulane School of Medicine, New Orleans, Louisiana. \\ ${ }^{6}$ Division of Hospital Medicine, University of California San Francisco, San Francisco, California.
}

\begin{abstract}
This article is also being published by the Journal of General Internal Medicine [Auerbach A, Flanders S, Centor R, Weber V, DeSalvo K, McGinn T. Challenges and Opportunities in Academic Hospital Medicine: Report from the Academic Hospital Medicine Summit. J Intern Gen Med 2009 (in press)].
\end{abstract}

The Academic Hospital Medicine Summit was supported by unrestricted funding from the Society of Hospital Medicine, the Society of General Internal Medicine, and the Association of Chiefs of General Internal Medicine. The funders had no input concerning the content or format of the summit proceedings or this publication.

Andrew Auerbach is supported by a K08 research and training grant (K08 HS11416-02) from the Agency for Healthcare Research and Quality. Karen DeSalvo is also supported by a K08 research and training grant (K08 HS15701-01A1) from the Agency for Healthcare Research and Quality.

Andrew Auerbach is a paid consultant $(<\$ 5000)$ for Merck.

\begin{abstract}
BACKGROUND: The field of hospital medicine is growing rapidly in academic medical centers. However, few organizations have explicitly considered the opportunities for and barriers to hospital medicine's development as an academic field in internal medicine.

OBJECTIVE: The objective was to develop consensus around key areas limiting or facilitating hospital medicine's
\end{abstract} development as an academic discipline.

DESIGN: The design was a consensus format conference of key stakeholders in academic hospital medicine.

RESULTS: The consensus group identified several issues impeding the development of academic hospital medicine as a recognized entity in academic settings, including extraordinarily rapid growth, increasingly preponderant nonteaching roles, and demands to perform nonclinical duties (such as quality improvement) not generally viewed as academic pursuits. The consensus group developed recommendations for addressing these concerns, specifically: 1) characterizing the optimal job description for an academic hospitalist, 2) developing better local and at-a-distance opportunities for training academic hospitalists in key aspects of early career success, and 3) advocating for the development of fellows and junior faculty researchers in hospital medicine.

SUMMARY: Fostering academic hospital medicine will help address these issues more effectively and will help the field while also attracting the next generation of generalists needed to care for an increasingly complex inpatient population. Journal of Hospital Medicine 2009;4:240-246. (C) 2009 Society of Hospital Medicine.

\section{KEYWORDS: career development, hospitalists as educators, research skills.}

The past decade has seen hospital medicine grow from fewer than 1000 hospitalists nationwide to more than $20,000 .^{1}$ In fact, survey data suggest that hospital medicine is the fastest growing field of internal medicine in the history of the US, and the growth of hospital medicine has produced a net increase in the number of generalists in the US. ${ }^{2}$

Although few direct estimates exist, academic hospital medicine (AHM) is also growing rapidly. ${ }^{1}$ Fueled by potential efficiency gains, a need for increased educational oversight of teaching services, and new residency work hour limitations, many academic medical centers and teaching hospitals have developed large hospital medicine programs.
Internal medicine residency graduates interested in general medicine are finding hospital medicine an increasingly popular career choice. As a result, AHM groups have many recent residency graduates with an average age that is generally younger than $40 .^{3}$

Over $85 \%$ of hospitalists are generalists and should find natural alliances with the nonhospitalist side of general internal medicine by collaborating in the course of clinical care, by teaching residents and students, or by designing quality improvement or research projects. In many academic centers, hospitalists are part of the division of general internal medicine, whereas in a few centers, hospitalists 
either have a separate division or lie outside the internal medicine department (employed by their hospitals).

Despite sharing a common training background and generalist mindset, many new academic hospitalists face different challenges than those faced by pure outpatient-based academic generalists. First, at many centers, the financial arrangements between the AHM group and the hospital discourage hospitalists from traditional academic pursuits and draw them into clinical, operational, or administrative duties (such as responsibility for utilization review) that, although locally valuable, may not count as academic products in themselves or may take time away from more academic activities. Close alignment between hospitals and AHM may result in hospital administrators dictating hospitalists' practice in a way that further impedes academic viability. Reductions in resident training hours and an increasing need to provide 24-hour coverage have facilitated growth in AHM into roles beyond those of the traditional academic generalist, such as medical comanagement of surgical patients and coverage of nonteaching services. ${ }^{4,5}$ The youth of the field may exacerbate these problems. Most academic hospitalist groups have few senior leaders, whether they are clinical-, education-, or research-focused. Young faculty need senior leaders as mentors to buffer them from relentless clinical demands that would compromise their hopes for academic success.

In order to better characterize these concerns and develop a shared work plan for future activities in support of AHM, the Society of Hospital Medicine (SHM) and the Society of General Internal Medicine (SGIM) convened an AHM consensus conference, a collaborative meeting developed and attended by representatives from SHM, SGIM, the Association of Chiefs of General Internal Medicine (ACGIM), the Association of Professors of Medicine, the Association of Program Directors in Internal Medicine, and the Association of Administrators in Internal Medicine. Using a structured consensus-building format, we identified key barriers and challenges to AHM, then developed potential solutions.

\section{Consensus Conference Format}

\section{Consensus Conference Steering Committee}

The consensus conference was developed first by the sponsoring professional societies (SGIM, SHM, and ACGIM) being asked to nominate 2 people to be part of the consensus conference steering committee. The steering committee's main functions were to identify key tasks for the consensus conference, invite consensus conference attendees, ensure adequate representation from all participating organizations, synthesize the results of the consensus conference, and work with the individual professional societies so that results from the consensus conference were acted upon in a coordinated and effective manner.

\section{Consensus Conference Prework}

The consensus conference co-chairs convened a series of conference calls in the spring of 2007, during which the steering committee developed a series of key areas to be explored during the conference. Topic areas were selected on the basis of the group's expertise and referred to past work by AHM taskforces convened by both SGIM/ACGIM and SHM.

The steering committee then invited stakeholders from each invited society so that each professional organization would provide at least 1 representative with expertise appropriate to 1 of the key domains identified:

1. Clinical and financial issues (within which topics such as optimal job descriptions and salary structures would be explored).

2. Teaching and education mission (within which topics such as mentorship for AHM junior faculty might be discussed).

3. Research and promotable activities (within which issues related to the development of promotable activities for AHM would be discussed).

Invitees to the consensus conference were assigned to one working group, given a general description of the potential areas within their domain, and instructed to consider a number of broad questions relevant to the topic area. These questions were as follows:

1. What are the key barriers to AHM in each key domain?

2. What viewpoints or barriers are the most pressing and/or actionable?

3. What solutions could be implemented or initiated in the next 1 to 3 years?

In order to facilitate discussion, consensus conference invitees were provided copies of findings from the SGIM/ ACGIM and SHM Academic Hospitalist Task Forces, preliminary results from a survey of AHM leaders, and key literature related to the field.

\section{Consensus Conference Format}

The AHM consensus conference followed a modified Delphi consensus-building format, in which the members of each working group developed findings relevant to their area, presented these viewpoints back to the overall group for feedback, and returned to their working group to refine their initial recommendations or move on to subsequent areas.

We used Day 1 of the meeting to confirm and refine lists of key barriers and opportunities to AHM. On Day 2, we developed actionable solutions and identified barriers with no ready solution but which were felt to be worth highlighting.

Each cycle of feedback ( 1 on Day 1 and 2 on Day 2) was used to identify additional barriers or opportunities prespecified by the steering committee, prioritize issues/opportunities, clarify uncertainties or point them out when they existed, and identify new areas requiring consensus. Between each cycle, workflow and interim results were summarized by the co-chairs and a professional meeting coordinator to ensure that the group felt consensus had been 


\section{TABLE 1. Challenges for Academic Hospital Medicine}

\begin{tabular}{|c|c|c|c|}
\hline Clinical and Financial Issues & Teaching and Education Mission & Research and Promotable Activities & Cross-Cutting Issues \\
\hline $\begin{array}{l}\text { - Hospitalists' functions more often } \\
\text { explicitly linked to hospital initiatives } \\
\text { (clinical care, quality improvement, } \\
\text { utilization, and throughput) }\end{array}$ & $\begin{array}{l}\text { - Distinguishing jobs that are } \\
\text { predominantly clinical (C-e) from those } \\
\text { that are predominantly education- } \\
\text { focused (c-E), which is important given } \\
\text { the high clinical burdens }\end{array}$ & $\begin{array}{l}\text { - Lack of a pipeline producing hospitalist } \\
\text { clinician investigators }\end{array}$ & $\begin{array}{l}\text { - Lack of leadership or negotiation skill } \\
\text { training }\end{array}$ \\
\hline \multirow[t]{2}{*}{$\begin{array}{l}\text { - Differing political, financial, and } \\
\text { scientific priorities between hospitalists } \\
\text { and administrators }\end{array}$} & $\begin{array}{l}\text { Further exacerbation of C-e/c-E } \\
\text { distinctions by the emergence of } \\
\text { uncovered services }\end{array}$ & $\begin{array}{l}\text { - Few national funders focusing on } \\
\text { inpatient general internal medicine }\end{array}$ & $\begin{array}{l}\text { - Little infrastructure for academic } \\
\text { functions }\end{array}$ \\
\hline & $\begin{array}{l}\text { - Little guidance on the best models for } \\
\text { each job type }\end{array}$ & $\begin{array}{l}\text { - Little recognition of quality improvement } \\
\text { as a promotable/testable activity }\end{array}$ & $\begin{array}{l}\text { - Rapidly moving/growing field } \\
\text { - Decreasing interest in general internal } \\
\text { medicine as a career path }\end{array}$ \\
\hline
\end{tabular}

Abbreviations: c-E, less clinician, mostly educator; C-e; mostly clinician, less educator.

achieved and to identify where additional work was required.

\section{Writing Group/Peer Review}

After the consensus conference adjourned, minutes were circulated to the group and approved, whereupon a summary of the meeting was reformatted into manuscript form. The manuscript was circulated to the steering committee, consensus conference attendees, and 2 selected peer reviewers as an additional check on the external validity of the study's results.

\section{Consensus Findings 1: Current Challenges in AHM (Table 1) Clinical and Financial Issues in AHM}

The consensus group identified misalignment of the mission of hospitals (which often provide substantial financial support for hospital medicine programs) and the mission of departments of internal medicine (or divisions of general internal medicine) in which adult hospitalists reside as a fundamental barrier in AHM. Misalignment of missions produces challenges to the development of hospitalist groups in that their primary funder, the hospital, focuses on clinical care delivery, productivity, efficiency, and, in some cases, participation in patient safety and quality improvement efforts, whereas academic departments place considerable value on education, research, grants received, dissemination of scholarly work, and the national reputation of its faculty. Further exacerbating this tension is the fact that hospitalists do not always reside within traditional academic divisions (such as divisions of general medicine) and are therefore viewed by the hospital and their peers as hospital employees more than academic faculty.

As yet, few hospital medicine programs have successfully integrated academic and clinical needs. In many AHM programs, clinical demands have trumped academic pursuits and, as a result, produced jobs that have frequent turnover. This occurs most often when hospitalists are hired by academic medical centers primarily to staff nonresident serv- ices. Hospitalists who join these academic programs expecting ample opportunity to teach and pursue scholarly work often leave when they realize these jobs differ little from those in community settings (with the exception of less pay and, in most cases, a less efficient clinical delivery system). This turnover contributes to the perception of hospitalists as transient nonacademic faculty. The participants felt that we needed to define the ideal academic hospitalist job description.

\section{Teaching and Education Mission in AHM}

Traditionally, faculty in academic medical centers have had prominent roles in resident teaching services, supervising medical residents, interns, and students. Hospitalists fill these roles at some institutions and in many cases have replaced senior faculty who are no longer able (because of competing demands from clinics or labs) or willing (because of an increased need for oversight and availability) to staff the teaching service. The teaching hospitalists start at these positions straight out of residency with little experience, training, or mentoring in how to succeed as a clinician educator. The creation of nonresident hospitalist services to address residency work hour requirements has removed many hospitalists from teaching opportunities as these services often have few if any teaching opportunities. The consensus group identified the lack of teaching opportunities and a lack of any formal preparation for those who do teach as the key challenges for new hospitalist clinician educators.

\section{Research and Promotable Activities in AHM}

Numerous challenges to promotion and success in hospital medicine research were identified. Most conference attendees felt that chairs of departments of medicine do not fully understand what the roles of academic hospitalists are, how they fit into the department's mission, or what is needed to better integrate hospitalists into the research and academic activities of the department. In addition, there are few 


\section{TABLE 2. Proposed Solutions for Overcoming Challenges Facing Academic Hospital Medicine}

\begin{tabular}{|c|c|c|}
\hline Solutions & Proposed Products & Challenge Domains Addressed* \\
\hline 1. Educate stakeholders & $\begin{array}{l}\text { - Workshops at professional society meetings (SHM, SGIM, ACGIM, } \\
\text { APM, and APDIM) } \\
\text { - Publications highlighting issues }\end{array}$ & - Addresses all domains \\
\hline 2. Define the sustainable job & - Data gathering and publication & - Clinical/financial \\
\hline 3. Quality improvement portfolio & - Development and dissemination of criteria for the QI portfolio & - Research/promotion \\
\hline 4. Hospitalist training/mentoring & - Academic hospitalist boot camp & $\begin{array}{l}\text { - Teaching/education } \\
\text { - Research/promotion } \\
\text { - Cross-cutting }\end{array}$ \\
\hline 5. Enhance research career pathways & - Advocacy for enhanced training programs and funding sources & - Research/promotion \\
\hline $\begin{array}{l}\text { 6. Improved relationships among general } \\
\text { medicine societies }\end{array}$ & - Society collaboration on product development & - Addresses all domains \\
\hline
\end{tabular}

Abbreviations: ACGIM, Association of Chiefs of General Internal Medicine; APDIM, Association of Program Directors in Internal Medicine; APM, Association of Professors of Medicine; QI, quality improvement; SGIM, Society of General Internal Medicine; SHM, Society of Hospital Medicine.

*Challenge domains include clinical/financial, education/teaching, research/promotion, and cross-cutting.

hospital medicine fellowship programs, and those that have been created focus primarily on improving teaching skills or quality improvement rather than on research or the development of academic products. Aspiring academic hospitalists could pursue research fellowship training in existing programs (ie, the Robert Wood Johnson Foundation), but few graduates currently pursue these opportunities, and federally funded fellowships (eg, the National Research Service Awards and Health Resources and Services Administration T32 awards) explicitly exclude physicians who are not focused on primary care research. The group noted that a number of Veterans Administration fellowships (such as the Quality Scholars programs) may provide avenues for the training of hospital medicine-focused researchers, but they have been underused.

For researchers who focus on hospital medicine, federal funding sources are limited for both career development awards (K-series) and later (R-series) grants, particularly those funding the quality and safety research that hospitalists often pursue. Agencies of the National Institutes of Health currently do not provide many opportunities for hospital-based general internal medicine research, and thus academic hospitalist research is undervalued by many promotion committees.

\section{Cross-Cutting Issues}

Challenges in leadership and mentorship were identified as cross-cutting. Many AHM programs are young, and so are their leaders. As a result, hospital medicine leaders often lack the experience and skills necessary to successfully negotiate for the support that is critical for the ideal program's success. As a young field, hospital medicine lacks faculty who have succeeded in careers as hospitalists, have been promoted in tenure tracks, and can mentor and guide young faculty through the complexities of academic medicine. Absent leadership and mentoring, few hospital medicine programs will succeed in traditional academic pursuits.

\section{Consensus Findings 2: Overcoming Challenges to the Development of AHM (Table 2)}

Summit attendees spent considerable time developing and refining solutions to the challenges described previously. Addressing the challenges resulted in a diverse group of proposed products that included educating key stakeholders, designing meetings, courses, or workshops, and gathering and disseminating data. There was considerable overlap among the solutions (Table 2).

\section{Outreach to and Education of Stakeholders in Academic Medicine}

The focus of the educational and outreach efforts suggested by the consensus group is to help leaders in academic medicine (not just AHM) and academic medical centers understand the challenges facing AHM. More importantly, efforts should reinforce the value of academic hospitalists to their hospital, department, and division. Efforts to engage these critical stakeholders to discuss and potentially address a number of the conference's proposed solutions are needed. Leaders include deans of medical schools, chairs of departments of medicine, division chiefs, and hospital administrative leadership.

Suggested outreach and educational activities included the publication of articles in key journals with the goal of increasing the visibility of AHM in professional societies as well as meetings and workshops focusing on teaching hospitalists and academic leaders methods to overcome challenges. Professional societies with a stake in AHM should better understand the challenges and position themselves to address these issues. The AHM task forces of SHM and SGIM can help give academic hospitalists a voice in having their needs addressed.

\section{Publications}

Articles have been commissioned in the following areas: descriptions of challenges and proposed solutions, best 
practices for nonresident hospitalist services, and metrics for the success of hospital medicine programs.

\section{Meetings/Workshops}

Meetings and workshops, sponsored by professional societies with a vested interest in AHM, were thought to be an effective way to address the needs of hospitalists, particularly those pursuing careers as clinician educators. Such workshops would provide skills in teaching and early career survival (eg, how to bill correctly) and in developing an educator's portfolio. Leadership training offerings, perhaps building on examples from SHM and ACGIM, were also thought to be valuable resources and venues that should be directed toward hospitalists, their chiefs, and relevant leaders.

\section{Defining a Sustainable Job Description for Academic Hospitalists}

The group strongly endorsed the need for transparent and readily available data aimed at developing sustainable academic hospitalist positions. For example, required information would include how academic jobs are constructed (in terms of months on service per year and the number of nights or weekends of coverage) and what successful programs and their hospitalists have found to be acceptable. Over the longer term, empiric comparisons based on key metrics are needed to not only help guide career development and retention but also facilitate negotiations for programmatic support.

The group pointed out that embedded in delineating an optimal academic hospitalist job description is the longstanding work of general medicine societies in supporting and fostering the development of clinician educators. In many ways, the pressures of academic physicians to be mostly clinician and less educator versus someone who focuses heavily on educational work is similar for hospitalists and outpatient generalists. Academic general internal medicine divisions hired many general internists in the early 1990s to expand the reach of academic medical centers and increase the outpatient base. ${ }^{6}$ Many university hospitals are now hiring hospitalists to provide the inpatient care for these patients, but residency work hour reductions have added a layer of complexity, creating the need for entirely new roles for academic generalists (such as surgical comanagement of medically complex patients). ${ }^{7,8}$ Past experiences in refining and reinforcing education as a key function (http://sgim.org/clinicianteach.cfm) would provide a template for future activities. Again, in the context of a rapidly growing number of nonteaching services, these descriptions have great importance.

\section{Development of a Quality-Improvement Portfolio Akin to an Educator's Portfolio}

Many hospitalists actively participate in administrative work related to quality improvement activities, and we should develop this additional pathway for promotable academic activities (eg, clinician administrator); however, such a pathway may not be recognized by all promotion committees. The group observed that many aspects of quality improvement are similar to those of education (eg, developing a curriculum, leading a team, evaluating a process, defining generalizability, and disseminating locally proven interventions) and as such would be amenable to the development of a quality improvement portfolio, which candidates could submit to promotion committees. Again, past work in developing the importance and value of the educator's portfolio would facilitate the development of a quality improvement portfolio, which would require endorsement from key stakeholders (eg, the Association of Professors of Medicine, SGIM, and SHM). ${ }^{9}$ Importantly, this work may also benefit many outpatient-based generalists who are increasingly focusing their careers on quality and safety improvement.

\section{Developing Mentoring and Training Opportunities \\ for Newly Hired and Junior Hospitalists}

We reached a strong consensus about the need to develop a retreat-format training opportunity by which junior academic hospitalists would be able to gain training in tasks critical to early-career success. These were envisioned as an initial 2- to 3-day meeting followed by mentorship at a distance and continued collaboration within the class of attendees. Topics would include key functions in AHM, such as becoming an effective attending physician and teacher, leadership, quality improvement, the business of medicine, effective billing, and maintaining a curriculum vitae. A number of professional societies have developed leadership or mentoring retreats, and at the time of this article's preparation, both regional and national efforts were underway to develop these products.

\section{Developing Training and Mentorship Pathways for Hospitalist Researchers}

There are few funded hospitalist researchers in the midcareer phase and a small but growing number of academic hospitalists entering the field with a focus on research. Enhancing a pipeline of researchers is a critical need for the field, as cementing AHM as an equal member of the academic medical community will be predicated on the successful development of hospitalist investigators. To this end, academic hospitalist groups should be encouraged to partner with other established research units (particularly general internal medicine) to create mentoring relationships and increase collaborative activities. The emergence of the Clinical and Translational Science Awards consortium sites, with a focus on implementation and effectiveness research, may also provide local opportunities for hospitalists to partner in research important for early-career grant submission. Furthermore, building the pipeline of academic hospitalist researchers will require a strong focus on identifying students and residents through outreach at individual sites as 
well as presentations at national meetings (eg, the American College of Physicians).

Two other issues were also thought to be important. First, professional societies should work to encourage funders of primary care-focused general medicine training programs (the National Research Service Awards and the Health Resources and Services Administration) to allow hospitalists to qualify for such critical research training. Second, continuing to advocate for increasing funding for implementation and effectiveness research, via either the Agency for Healthcare Research and Quality or individual agencies of the National Institutes of Health, will be key; the emergence of a medical effectiveness institute would also be a potential boon.

\section{Improving Relationships Between the Professional Homes of Academic Generalists}

Relationships between outpatient-based general medicine and hospital medicine were rocky as the field of AHM first took shape, and some residua of initial tensions persist a decade later. These tensions persist in part because hospitalists remain underdeveloped members of the academic community, and this perhaps gives some license to aver that hospitalists are merely transient faculty in a stage between residency and fellowship hired to improve throughput.

Overcoming this perception will require more engagement between academic generalists of all types, not less. The consensus group felt strongly that there need not be a single professional home for academic hospitalists and that generalists should be willing and even encouraged to selfidentify as hospital- or clinic-focused, much as they might be geriatrics-focused, informatics-focused, or women's health-focused. In fact, in some academic centers, a few generalists have successfully integrated themselves into both clinic-based and hospitalist roles. In this way, the emergence and growth of AHM should be viewed as a boon to the practice of general medicine, not a challenge.

\section{Resources}

Much of what is proposed to enhance AHM will require resources. Academic hospitals have a vested interest in supporting AHM as a way to reduce turnover in a group that is increasingly critical for hospital operations, not to mention key leadership roles. Negotiating for these resources should emphasize that hospitals benefit directly from the revenue and margin that comes from incremental hospital admissions, collect most of the federal graduate medical education dollars, and benefit from improved care processes that are a result of hospitalist quality improvement efforts.

Deans and Departments, a key audience for the conference findings, also have a clear stake in fostering a less transient, more professionally satisfied and academically successful work force, particularly when hospitalists are increasingly the key educators of medical residents. Moreover, schools have a vested interest in the academic accomplishments and national reputation of their hospitalists. The financial arrangements will be unique to each setting and institution, and it is clear that the sources to be tapped will vary from site to site, but these resources are clearly necessary for the field.

\section{Conclusions}

AHM is at a crossroads. Unparalleled growth has created a large cadre of hospitalists who are struggling to meet the clinical demands of practice and the requirements for academic promotion; this situation will likely lead to, at a minimum, worsening problems with faculty turnover, and even greater losses of talented and passionate clinicians from the field of academic General Internal Medicine.

The challenges are numerous but not insurmountable, and our process identified issues and potential solutions which address clinical, educational, and research aspects of academic hospitalists' lives. We acknowledge that our findings are most relevant to hospitalists at academic medical centers or large academically oriented community teaching hospitals rather than hospitalists at community hospitals whose work is predominantly clinical with smaller teaching roles. However, we feel the academic hospitalists we targeted are in greater need of assistance. We believe that the most important issues are unsustainable, nonacademic positions, poor job preparation and training, inadequate prioritization of academic roles, and insufficient leadership and mentoring within the field.

It is the hope of all the consensus conference attendees that efforts focusing on academic hospitalists in the short term are not viewed as effort diverted from general internal medicine; in fact, the group felt that while many of the products of the consensus conference were probably most needed by AHM in the short term, these same solutions would likely be useful to outpatient-based generalists as well. Despite the concerns and challenges outlined, the consensus conference group was also very hopeful that, in the setting where resources and collaboration are appropriately marshaled, that AHM will flourish quickly. In doing so, academic hospitalists will become better role models for residents and students, attracting the next generation of generalists needed to provide care to an increasingly complex patient population, and further advance the mission of General Internal Medicine.

\footnotetext{
Acknowledgements

The authors thank Dr. Jeff Glasheen and Dr. Robert Wachter for their comments on an earlier version of this article. In addition, the authors thank the following conference participants: Dan Brotman, MD, Johns Hopkins University; Deborah M. DeMarco, MD, President of the Association of Program Directors in Internal Medicine; Jeff Glasheen, MD, University of Colorado; Rusty Holman, MD, President of the Society of Hospital Medicine; Martha A. Hooven, President of the Administrators of Internal Medicine; Peter Kaboli, MD, University of Iowa; David O Meltzer, MD, PhD, University of Chicago; Vikas Parekh, MD, University of Michigan; Russell Phillips, MD MPH, Harvard Medical School; Sanjay Saint, MD, MPH, University of Michigan; Barbara Schuster, MD, President of the Association of Professors of Medicine; Brad Sharpe, MD, University of California
}

2009 Society of Hospital Medicine DOI 10.1002/jhm.497

Published online in wiley InterScience (www.interscience.wiley.com). 
San Francisco; Jeff Wiese, MD, Tulane University; David Kushner, Facilitator of the Kushner Companies; Geri Barnes, Support Staff of the Society of Hospital Medicine; and Amy Woodward, Support Staff of the Society of General Internal Medicine.

\section{Address for correspondence and reprint requests:}

Andrew Auerbach, MD, MPH, Division of Hospital Medicine,

University of California San Francisco, 505 Parnassus Avenue, Box

0131, San Francisco, CA 94143; Telephone: 415-502-1412; Fax: 415-

514-2094; E-mail: ada@medicine.ucsf.edu Received 6 August 2008; revision received 18 December 2008; accepted 21 January 2009.

\section{References}

1. Kralovec PD, Miller JA, Wellikson L, Huddleton JM. The status of hospital medicine groups in the United States. J Hosp Med. 2006;1:75-80.

2. Auerbach AD, Chlouber R, Singler J, Lurie JD, Bostrom A, Wachter RM. Trends in market demand for internal medicine 1999 to 2004: an analysis of physician job advertisements. J Gen Intern Med. 2006;21:1079-1085.
3. Society of Hospital Medicine. 2006 Hospital Medicine Survey. Available at: http://www.hospitalmedicine.org/content/navigationmenu/media/mediakit/ media_kit.htm. Accessed January 2009.

4. Fletcher KE, Underwood W III, Davis SQ, Mangrulkar RS, McMahon LF Jr, Saint S. Effects of work hour reduction on residents' lives: a systematic review. JAMA. 2005;294:1088-1100.

5. Saint S, Flanders SA. Hospitalists in teaching hospitals: opportunities but not without danger. J Gen Intern Med. 2004;19:392-393.

6. UCLA rewrites the script for academic networks. Med Netw Strategy Rep. 1998;7:1-5.

7. Fletcher KE, Davis SQ, Underwood W, Mangrulkar RS, McMahon LF Jr, Saint S. Systematic review: effects of resident work hours on patient safety. Ann Intern Med. 2004;141:851-857.

8. Sehgal NL, Wachter RM. The expanding role of hospitalists in the United States. Swiss Med Wkly. 2006;136:591-596.

9. Simpson D, Hafler J, Brown D, Wilkerson L. Documentation systems for educators seeking academic promotion in U.S. medical schools. Acad Med. 2004;79:783-790. 